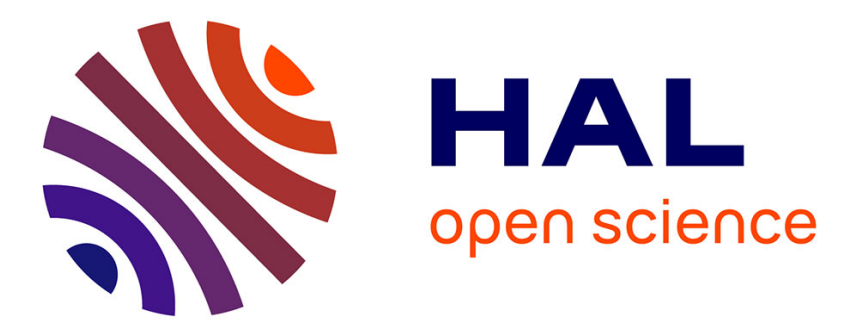

\title{
Long-term thermo-mechanical behaviour of energy piles in clay
}

van Tri Nguyen, Nanwangzi Wu, Yixiang Gan, Jean-Michel Pereira, Anh

Minh A.M. Tang

\section{- To cite this version:}

van Tri Nguyen, Nanwangzi Wu, Yixiang Gan, Jean-Michel Pereira, Anh Minh A.M. Tang. Longterm thermo-mechanical behaviour of energy piles in clay. Environmental Geotechnics, 2020, 7 (4), pp.237-248. 10.1680/jenge.17.00106 . hal-02879341

\section{HAL Id: hal-02879341 \\ https://hal-enpc.archives-ouvertes.fr/hal-02879341}

Submitted on 23 Jun 2020

HAL is a multi-disciplinary open access archive for the deposit and dissemination of scientific research documents, whether they are published or not. The documents may come from teaching and research institutions in France or abroad, or from public or private research centers.
L'archive ouverte pluridisciplinaire HAL, est destinée au dépôt et à la diffusion de documents scientifiques de niveau recherche, publiés ou non, émanant des établissements d'enseignement et de recherche français ou étrangers, des laboratoires publics ou privés. 
$1 \quad$ Long-term thermo-mechanical behaviour of energy pile in clay

2

V. T. NGUYEN ${ }^{1}$, N. WU ${ }^{2}$, Y. GAN $^{2}$, J. M. PEREIRA ${ }^{1}$, A. M. TANG ${ }^{1}$

$3{ }^{1}$ Laboratoire Navier, UMR 8205, École des Ponts ParisTech, IFSTTAR, CNRS, UPE, France

4

${ }^{2}$ School of Civil Engineering, The University of Sydney, NSW 2006, Australia

5

6 Corresponding author:

$7 \quad$ Dr. Anh Minh TANG

8

$9 \quad$ Ecole des Ponts ParisTech

10 Laboratoire Navier/Géotechnique (CERMES)

11 6-8 avenue Blaise Pascal

1277455 MARNE-LA-VALLEE

13 France

$14 \quad$ Tel: +33.1 .64 .15 .35 .63$

15 http://navier.enpc.fr

16 Email: anhminh.tang@enpc.fr

17

18 
ABSTRACT

In engineering practice, energy pile foundations are often designed for the lifetime of the building. Thermal exchange between a pile and the surrounding soil depends on the annual energy needs of the building, as heating mode in winter and cooling mode in summer. Thus, energy pile foundations will undergo a heating-cooling cycle per year. In the present work, an experimental method based on a small-scale pile model installed in saturated clay was used to study the thermo-mechanical behaviour of energy pile under thermal cycles. 30 cycles were applied (to represent a 30-year period if we neglect the daily cycles) while the pile head load was maintained constant. Four tests were performed corresponding to pile head loads equal to $0,20 \%, 40 \%$ and $60 \%$ of pile resistance. The results obtained show the increase of irreversible pile head settlement with the thermal cycles. In order to better interpret the experimental results, the finite element method is used to simulate numerically the experiments. That allows highlighting the important role of pile thermal contraction/expansion in the pile/soil interaction under thermo-mechanical loading.

KEYWORDS: energy pile, numerical modelling, physical modelling, saturated clay, thermal cycles, thermo-mechanical behaviour.

\section{INTRODUCTION}

Pile foundations are used to erect a structure on an underground with poor load bearing properties. The energy piles (also called "heat exchanger piles") are the foundation piles that are used also as heat exchangers. A system of heat exchanger pipes is embedded in such piles allowing the exchanges of thermal energy between the ground and the building via a fluid circulating in the pipes. This system combined with a heat pump allows extracting heat from the soil in winter and re-injecting back heat to the soil in summer (Abuel-Naga et al., 2015; 
44 de Santayanal et al., 2019). Thus, energy pile foundation is subjected to a heating-cooling cycle per year, which reflects seasonal temperature variations. These annual thermal cycles would then modify the soil/pile interaction from the thermo-mechanical point of view. In spite of various studies on the thermo-mechanical behaviour of energy piles, few works have investigated their long-term behaviour. Actually, to deal with this aspect, some studies investigated the mechanical behaviour of energy piles subjected to numerous thermal cycles, which represent the seasonal pile temperature variations ( $\mathrm{Ng}$ et al., 2014; Pasten and Santamarina, 2014; Suryatriyastuti et al., 2014; Di Donna and Laloui, 2015; Olgun et al., 2015; Saggu and Chakraborty, 2015; Ng et al., 2016; Bidarmaghz et al., 2016; Vieira and Maranha, 2016; Nguyen et al., 2017). In these studies, numerical methods are usually used and experimental methods are mainly based on physical modelling.

Among the numerical methods, the conventional load transfer method is the simplest one. Suryatriyastuti et al. (2014) used this method, combined with additional mechanisms for predicting degradation behaviour of pile-soil interface under thermal cycles, and investigated the behaviour of free- and restraint-head pile in loose sand. The results show a ratcheting of pile head settlement under a constant working load and a decrease in pile head force for the restraint-head pile after 12 thermal cycles. Pasten and Santamarina (2014) developed a modified one-dimensional load transfer model to predict the displacement of pile elements. The results show that the axial force changes mainly in the middle of pile length when the pile works under a heating phase. But in a cooling phase the axial force changes are negligible. Besides, the irreversible settlement of pile reaches a plateau after several thermal cycles.

Besides the load transfer method, the finite element method is also used to investigate longterm thermo-mechanical behaviour of energy piles. Saggu and Chakraborty (2015) 
investigated the behaviour of a floating and end-bearing pile in loose and dense sand under various thermal cycles by using the finite element method. The result shows an important settlement of the pile after the first thermal cycle. A similar result can be found in the numerical study of Olgun et al. (2015) where pile head displacement and axial stress were investigated under three different climatic conditions for 30 years. After 30 annual thermal cycles, even if the pile was progressively cooled, the axial stress along the pile tended to increase. A decrease in axial stress was observed during heating. This was explained by the difference in the thermal dilation between the pile and the soil during the thermal loading process. $\mathrm{Ng}$ et al. (2016) studied the horizontal stress change of soil element close to the pile when the pile is subjected to 50 heating-cooling cycles. The results show that the horizontal stress along the pile depth decreased with thermal cycles. In addition, the irreversible settlement of pile due to the decrease of the shaft resistance leads to the densification of soil below the pile toe and thus the decrease of the rate of pile's settlement.

Few studies have investigated the long-term thermo-mechanical behaviour of energy pile in clay. Di Donna and Laloui (2015) have developed a numerical model to estimate the additional displacement of pile and stress-strain state at the soil-pile interface. The result indicates that the upper part of pile heaves in the heating phase and settles in the cooling phase. The irreversible settlement of the pile is observed in the first cycle, but in the following cycles the vertical displacement of the pile is almost reversible. A greater plastic strain was obtained within the soil mass at points located close to the soil-pile interface. Vieira and Maranha (2016) investigated the behaviour of a floating pile model in clay soil under different constant static loads and seasonal temperature variations during five years using the finite element method. The considered soil is saturated and normally consolidated. The results indicate that when the pile works with a high factor of safety, its displacement is 
reversible during the thermal cycles. However, a low factor of safety induces an increase in axial stresses while the rate of irreversible settlement reduces with the number of cycles.

95

Beside the numerical studies mentioned above, few experimental studies have been performed to investigate the long-term behaviour of energy piles in clay. $\mathrm{Ng}$ et al. (2014) used centrifuge modelling to study the thermo-mechanical behaviour of energy piles constructed in lightly and heavily over-consolidated clay under five thermal cycles. The results show that the most irreversible settlement of pile was observed in the first thermal cycle, and then in the following cycles the settlement increases at a lower rate. After 5 cycles the cumulative settlement was about $3.8 \% \cdot \mathrm{D}$ ( $\mathrm{D}$ being the pile diameter) for a pile in the lightly over-consolidated clay, and $2.1 \% \cdot \mathrm{D}$ in the case of heavily over-consolidated clay.

In the present work, the long-term thermo-mechanical behaviour of an energy pile in clay is investigated both by physical and numerical modelling. First, a small-scale pile model installed in saturated clay was used. 30 thermal cycles were applied while the pile head load was maintained constant at $0,20 \%, 40 \%$ and $60 \%$ of pile bearing capacity. Second, the finite element method is used to simulate numerically the experiments. The results of the two methods are finally analysed simultaneously to better identify the main mechanisms controlling the thermo-mechanical behaviour of energy pile under several thermal cycles. The novelty of the work consists in integrating results of a small-scale pile model (physical modelling) with those obtained by numerical modelling (finite element numerical model). As referred above few (and very recent) works can be found in the literature dealing with the long-term mechanical effect on energy geostructures (energy piles, in the present case) under thermal cycles. 
PHYSICAL MODELING

119 The pile model is made of an aluminium tube with internal and external diameters of $18 \mathrm{~mm}$ 120 and $20 \mathrm{~mm}$, respectively. The length of the tube is $800 \mathrm{~mm}$ and it is sealed at the bottom. Its 121 external surface was coated with sand to imitate the roughness of a full-scale bored pile. 600 $122 \mathrm{~mm}$ of the pile was embedded in saturated clay (see Figure 1).

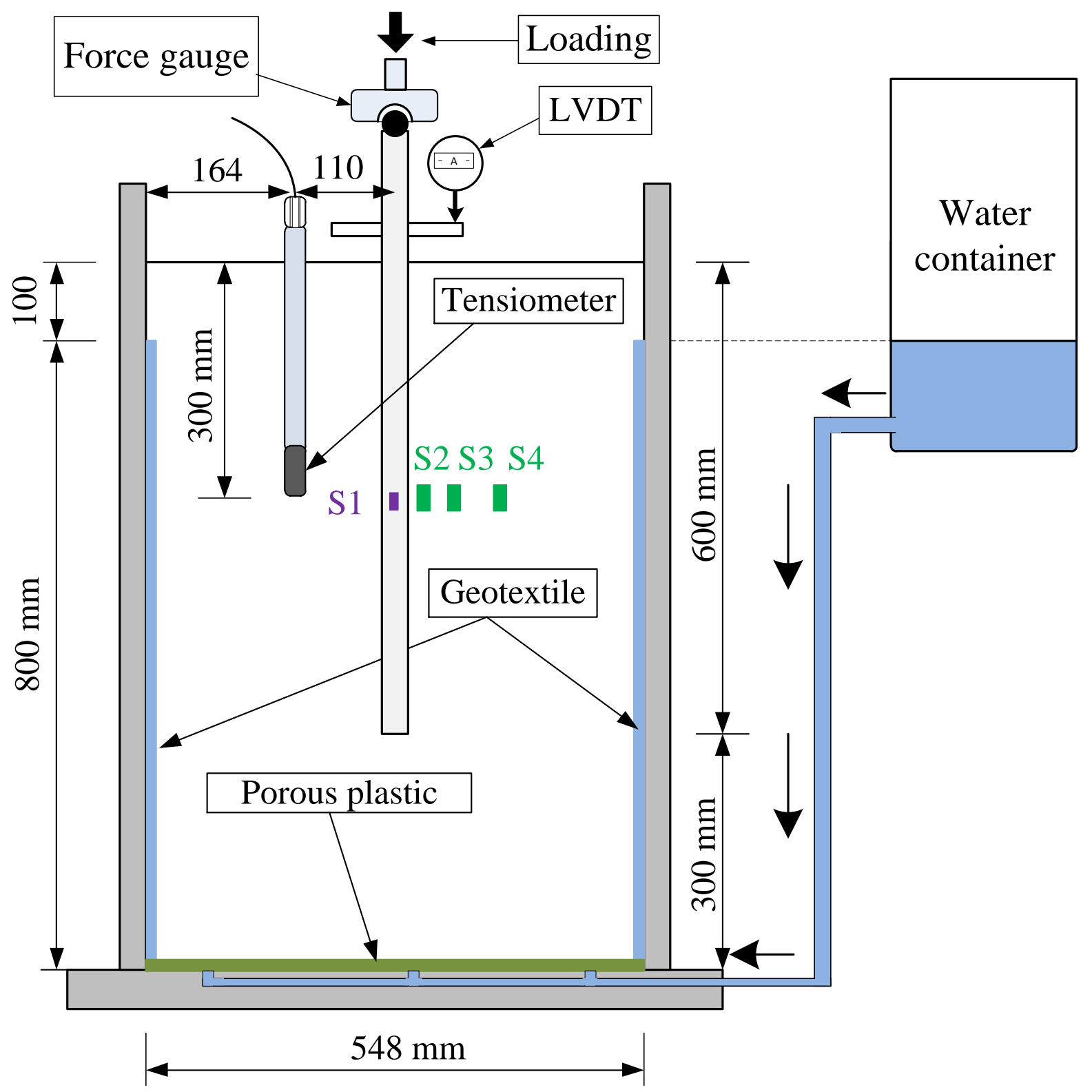

S1: Temperature transducer inside the pile

$\mathrm{S} 2 \div 4$ : Temperature transducer distributed in soil

Figure 1. Experiment setup 
126 The pile temperature is controlled by a metallic U-tube inserted inside it and connected to a cryostat. A temperature sensor (accuracy equals $\pm 0.01^{\circ} \mathrm{C}$ ) is embedded inside the pile, at 300 mm depth, to monitor its temperature during the experiments. The axial load applied to the pile head is controlled by deadweight (more details can be found in Yavari et al., 2014 on a

130 similar setup) and measured by a force sensor. The pile head displacement is measured by a displacement sensor (LVDT) with an accuracy of $\pm 0.001 \mathrm{~mm}$. Temperature in soil is measured by three sensors embedded at 300-mm depth and 20, 40, $80 \mathrm{~mm}$ from the pile axis.

134 Speswhite Kaolin clay was used in this study. It has a clay fraction of $30 \%$, a liquid limit of $13557 \%$, a plastic limit of $33 \%$ and a particle density of $2.60 \mathrm{Mg} / \mathrm{m}^{3}$. Clay powder was mixed with water by using a soil mixer to achieve a water content of $29 \%$. It is then stored in a sealed box for one month for moisture homogenization. Compaction was performed, by layer of 50-mm thickness, using an electrical vibratory hammer. The soil mass used for the compaction of each layer was controlled to obtain a dry density of $1.45 \mathrm{Mg} / \mathrm{m}^{3}$ (degree of 140 saturation equals $95 \%$ and void ratio equals 0.79 ). After the compaction of the first six layers, 141 the model pile was installed in place, and the remaining soil layers were completed. At the vicinity of the pile model, a small metal hammer was used to avoid damaging the pile.

144 To control the quality of the compaction procedure, soil samples (20 $\mathrm{mm}$ in diameter) were 145 cored from the compacted soil mass for the determination of dry density and water content.

146 The created hole was refilled afterwards prior to the test with energy pile. Results show that 147 the dry density and the water content are relatively uniform with depth and they are close to 148 the target values (Figure 2). 


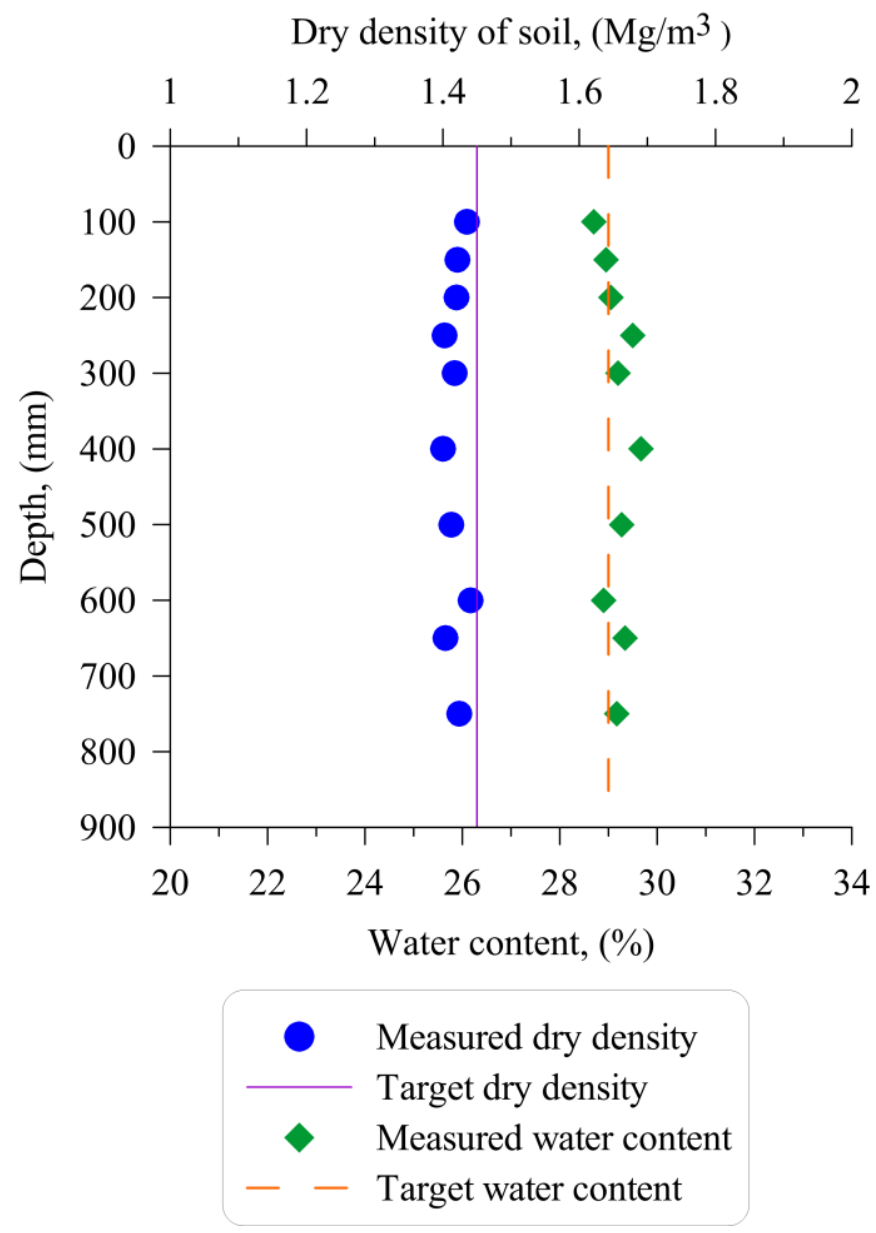

Figure 2. Dry density and water content of compacted soil

152 In the work of Yavari et al. (2016a), re-saturating a similar soil mass from the bottom took 153 several months. In the present work, to speed up this phase, a porous plastic plate was installed at the bottom of the soil container and a thin geotextile layer was installed between the container internal surface and the soil mass (see Figure 1). Thus, water from the container can easily flow through the small holes at the bottom of the soil container and diffuse into the

157 soil mass via the porous plastic plate and the surrounding geotextile. The water level in the 158 water container was kept $100-\mathrm{mm}$ below the soil surface to avoid water overflow on the soil surface. During the saturation, a tensiometer T8 (T8-UMS, 2008) was used to control the soil suction at 300-mm depth and 110-mm far from the pile's axis (see Figure 1). Result in the

161 Figure 3 shows that after 18 days of saturation the soil suction at the tensiometer position is 
very close to zero. The tensiometer was then removed and the resulting hole was refilled to avoid its influence on the thermo-mechanical behaviour of the pile. The saturation process was kept for 45 days in total to ensure the full saturation of the soil mass. In should be noted that, during the saturation, the soil container was covered on its surface to avoid water evaporation and heat exchange. Moreover, the saturation system was maintained during the subsequent thermo-mechanical experiment to ensure that the soil is always saturated.

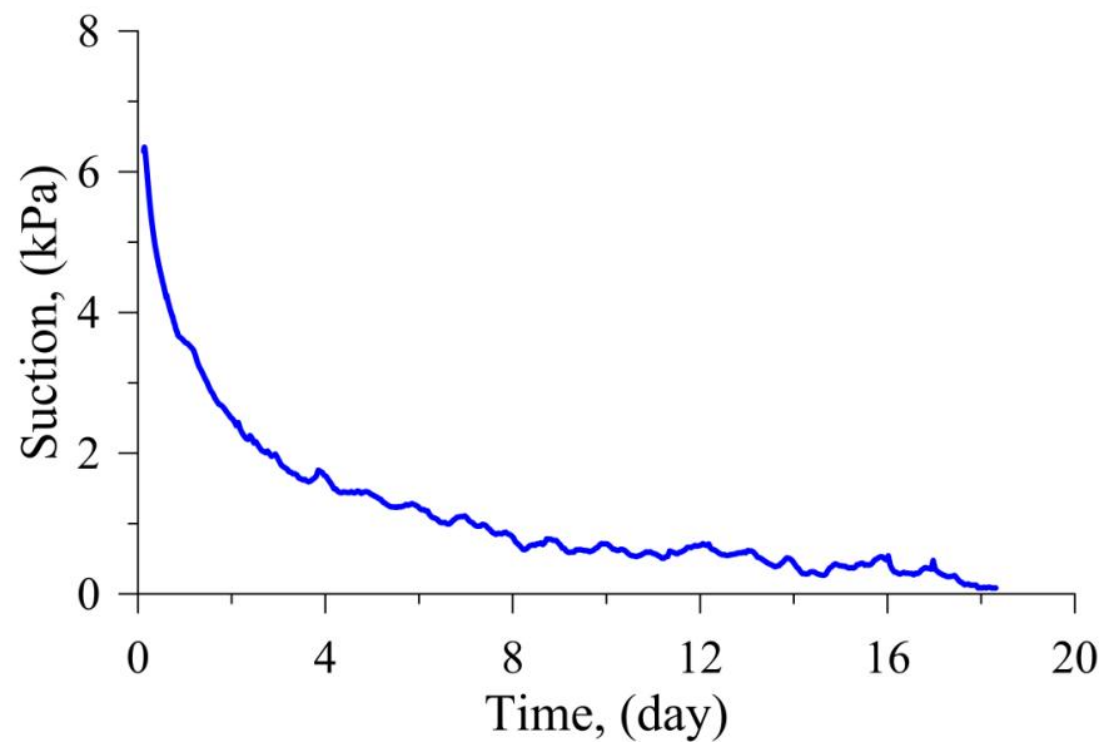

Figure 3. Evolution of soil suction during the saturation process (measured by tensiometer)

Before conducting the experiment, temperature of soil and pile was kept at $20{ }^{\circ} \mathrm{C}$ for one week. This temperature is close to the room temperature during that period. After the saturation process, the pile was initially subjected to a mechanical load (test A1) to determine its ultimate bearing capacity. A series of load steps was applied to the pile head with

177 increments of $50 \mathrm{~N}$, each loading step being maintained for one hour, following the French

178 Standard (Afnor, 1999). The results, shown in Figure 4, are similar to those obtained by 179 Yavari et al. (2016a). That confirms the repeatability of the applied experimental procedure. 
181 In the test A1, the pile was loaded up to $500 \mathrm{~N}$, which corresponds also to the pile's bearing 182 capacity. After this test, the pile head load was removed. In the test A2, 30 thermal cycles 183 were performed while no load was applied to the pile head. Afterward, the pile head was 184 loaded up to $20 \%$ of the pile's capacity prior to the application of 30 thermal cycles (test A3 185 shown in Figure 4). At the end of these cycles, the pile head load was removed and then a 186 load corresponding to $40 \%$ of the pile's capacity was applied. 30 thermal cycles were then 187 performed under this load (test A4). A similar procedure was applied for test A5 188 corresponding to $60 \%$ of pile's capacity. This procedure is similar to that applied by Yavari et 189 al. (2016a) where only one thermal cycle was applied per load step. All the five tests were 190 performed on the same soil mass. The mechanical test (A1) was performed at first to identify 191 the pile's capacity. That allowed better define the programme for the subsequent thermo192 mechanical tests (A2-A5). Yavari et al. (2016a) found that loading the pile to its ultimate 193 bearing capacity and then unload it did not modify its behaviour during the subsequent tests. 

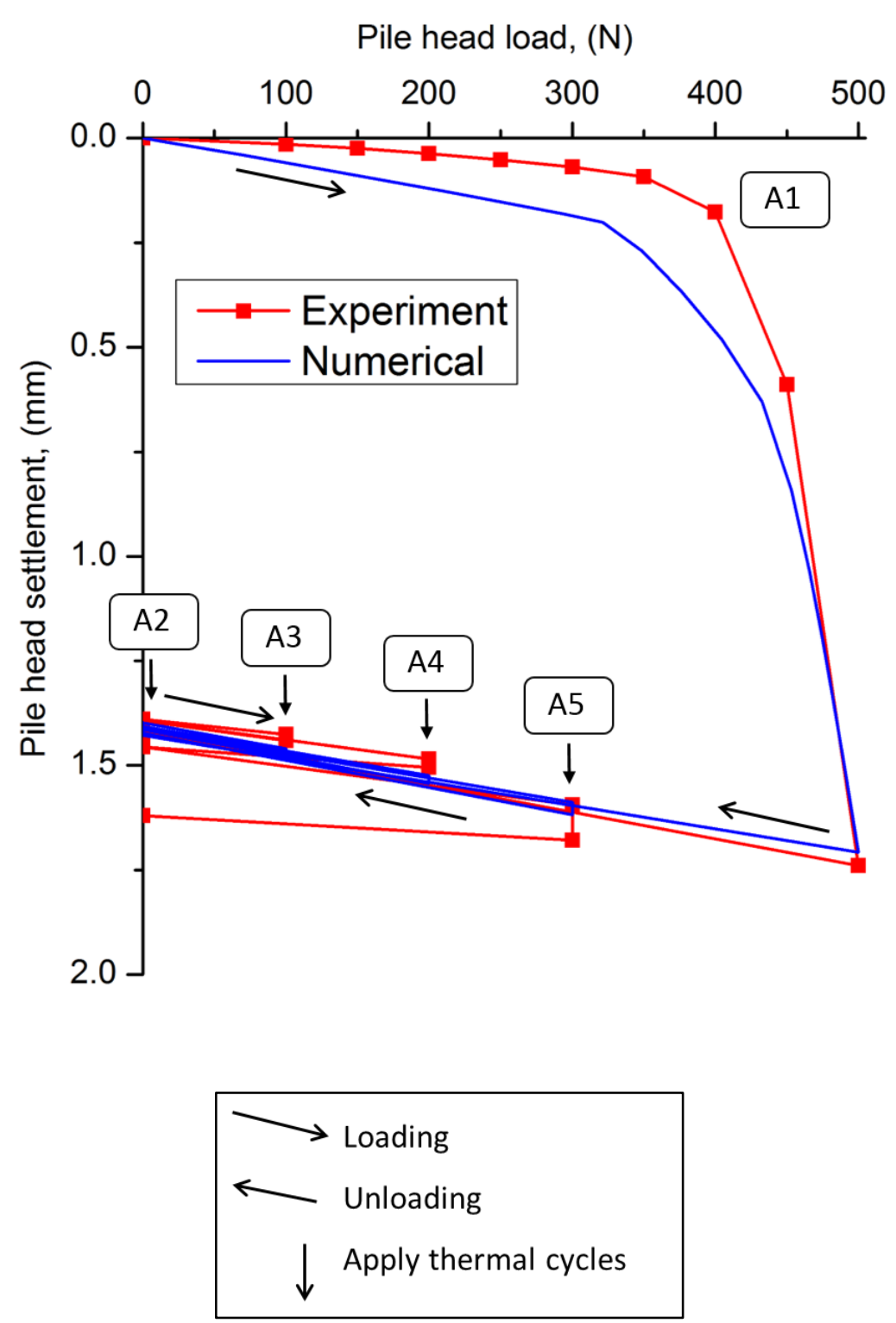

196 Figure 4. Pile head load displacement curve: A1 is a purely mechanical test; A2, A3, A4 and

A5 are thermo-mechanical tests

199 For each thermal cycle, the pile temperature is increased and then decreased with a variation 200 of $\pm 1^{\circ} \mathrm{C}$ around the initial value (shown later as the thermal sensor $\mathrm{S} 1$ in Figure 8). This range 201 is much smaller than the temperature variation of the energy piles which can reach up to $202 \pm 20^{\circ} \mathrm{C}$ (Di Donna and Laloui, 2015; Olgun et al., 2015). Actually, in this small-scale model, 203 the dimension of the pile is 20 times smaller than a full-scale pile of $0.4 \mathrm{~m}$ in diameter and 12 204 m length. As a consequence, the strain related to the mechanical load is 20 times smaller than 
that at the full scale (Laloui et al., 2006; $\mathrm{Ng}$ et al., 2014). For this reason, the temperature variation was reduced 20 times in order to have a thermal strain of the pile 20 times smaller than that at the full scale. Each thermal cycle is completed within 24 hours, which started with a heating period of 4 hours, and followed by a cooling period of 4 hours, finally the remaining time corresponded to active heating to return to the initial temperature.

210

\section{NUMERICAL MODELING}

\section{Axisymmetric finite element model}

213 The finite element analysis was performed by using the commercial FEA software, ABAQUS

214 V6.16. To model the physical experiment, two-dimensional axisymmetric model is 215 established (as shown in Figure 5) and fully coupled 4-node temperature-pore pressure216 displacement element (CAX4PT) and 4-node bilinear displacement-temperature element 217 (CAX4T) are used for the regions of soil and pile, respectively. Soil is assumed fully saturated throughout the loading cycles and the top $100 \mathrm{~mm}$ capillary zone in physical model is ignored. Pore pressure at top surface of soil is opened to air but no heat flow escapes from top surface. Circular hollow section aluminium pile is modelled by solid pile with the equivalent mass density. Soil is modelled by the modified Cam-clay model and the pile is described by linear-elasticity model. For contact properties, the friction coefficient at the soilpile interface is assumed to be $\tan \phi$, where $\phi$ is the soil friction angle. Note that a relatively large thermal conductance is chosen at pile-soil interface to reduce the interfacial thermal contact resistance. Lateral pressure coefficient is assumed based on the Meyerhof correlation, $K_{0}=(1-\sin \phi) O C R^{0.5}$, by taking the pressure at $2 / 3$ depth of pile for averaging pressure along the pile to estimate $K_{0}$, and OCR is approximately 160 . The calculation of OCR is based on the ratio of the historical maximum pressure and the current experienced pressure. 
NCL, i.e., $560 \mathrm{kPa}$ with the experimentally measured void ratio of 0.79 . As a result, $K_{0}=8$ is adopted for the numerical simulation and it is within a reasonable range since preparation of physical model involves pre-compaction process. All parameters in simulation are summarized in Table 1 and Table 2, and the constitutive parameters of soil can be referred to Lv et al. (2017). Initial temperature for the entire numerical model is assumed $20^{\circ} \mathrm{C}$ as the case of the physical model. Bottom and side boundaries are set as the constant temperature of $20^{\circ} \mathrm{C}$. Deformation of soil is fully fixed at the bottom and only horizontally fixed at the side, while the top surface is free to deform. Finite sliding formulation is used at soil-pile interface. Temperature variation with time in physical experiment is deemed to be an input parameter to investigate settlement occurring under the cyclic thermal loading condition. To simplify the model, the entire pile is going to experience temperature variation uniformly instead of the water circulation process in experiment. Thirty heating and cooling cycles are applied in every thermal loading stage after the given mechanical load. One complete thermal cycle includes four different thermal phases: initial, heating, cooling, and reheating, which will

244 induce settlement fluctuation.

Table 1. Parameters of pile and soil in numerical modelling

\begin{tabular}{|l|c|c|}
\hline Parameters & $\begin{array}{c}\text { Pile } \\
\text { (CHS aluminium) }\end{array}$ & $\begin{array}{c}\text { Clay } \\
\text { (Speswhite Kaolin Clay) }\end{array}$ \\
\hline Constitutive model & Linear-elastic & Modified Cam-clay \\
\hline Dry density $\left(\mathrm{Mg} / \mathrm{m}^{3}\right)$ & 1.32 & 1.45 \\
\hline $\begin{array}{l}\text { Volumetric weight at saturated } \\
\text { state }\left(\mathrm{kN} / \mathrm{m}^{3}\right)\end{array}$ & N/A & 18.53 \\
\hline Young's modulus E $(\mathrm{kPa})$ & $1.3 \mathrm{E} 7$ & N/A \\
\hline Poisson's ratio $\mathrm{v}^{*}$ & 0.33 & 0.25 \\
\hline Slope of critical state line $\mathrm{M}^{*}$ & N/A & 0.98 \\
\hline Slope of virgin consolidation line & N/A & 0.14 \\
\hline
\end{tabular}




\begin{tabular}{|l|c|c|}
\hline$\lambda^{*}$ & & \\
\hline Slope of swelling line $\kappa^{*}$ & N/A & 0.012 \\
\hline Initial void ratio $e_{0}{ }^{*}$ & N/A & 0.79 \\
\hline Void ratio after compaction $e_{1}$ & N/A & $25^{\circ}$ \\
\hline Friction angle $\phi^{*}$ & N/A & $1 \mathrm{E}-8$ \\
\hline Permeability $k(\mathrm{~m} / \mathrm{s})^{*}$ & N/A & $1 \mathrm{E}-6$ \\
\hline Thermal expansion $\left({ }^{\circ} \mathrm{C}\right)$ & $2.3 \mathrm{E}-5$ & 1.5 \\
\hline Thermal conductivity $\left(\mathrm{W} / \mathrm{m}^{\circ} \mathrm{C}\right)$ & 237 & $1.269 \mathrm{E} 3$ \\
\hline Specific heat capacity $\left(\mathrm{J} / \mathrm{kg}^{\circ} \mathrm{C}\right)$ & & $9 \mathrm{E} 2$ \\
\hline
\end{tabular}

* Soil properties are adopted from Lv et al. (2017).

247 Table 2. Other relevant parameters in numerical modelling

\begin{tabular}{|l|c|}
\hline $\begin{array}{l}\text { Volumetric weight of water } \\
\left(\mathrm{kN} / \mathrm{m}^{3}\right)\end{array}$ & 9.81 \\
\hline Friction coefficient tan $\phi$ & 0.47 \\
\hline $\begin{array}{l}\text { Interfacial thermal conductance } \\
\left(\mathrm{W} /{ }^{\circ} \mathrm{C} * \mathrm{~m}^{2}\right)\end{array}$ & 500 \\
\hline Lateral earth coefficient, $K_{0}$ & 8 \\
\hline
\end{tabular}




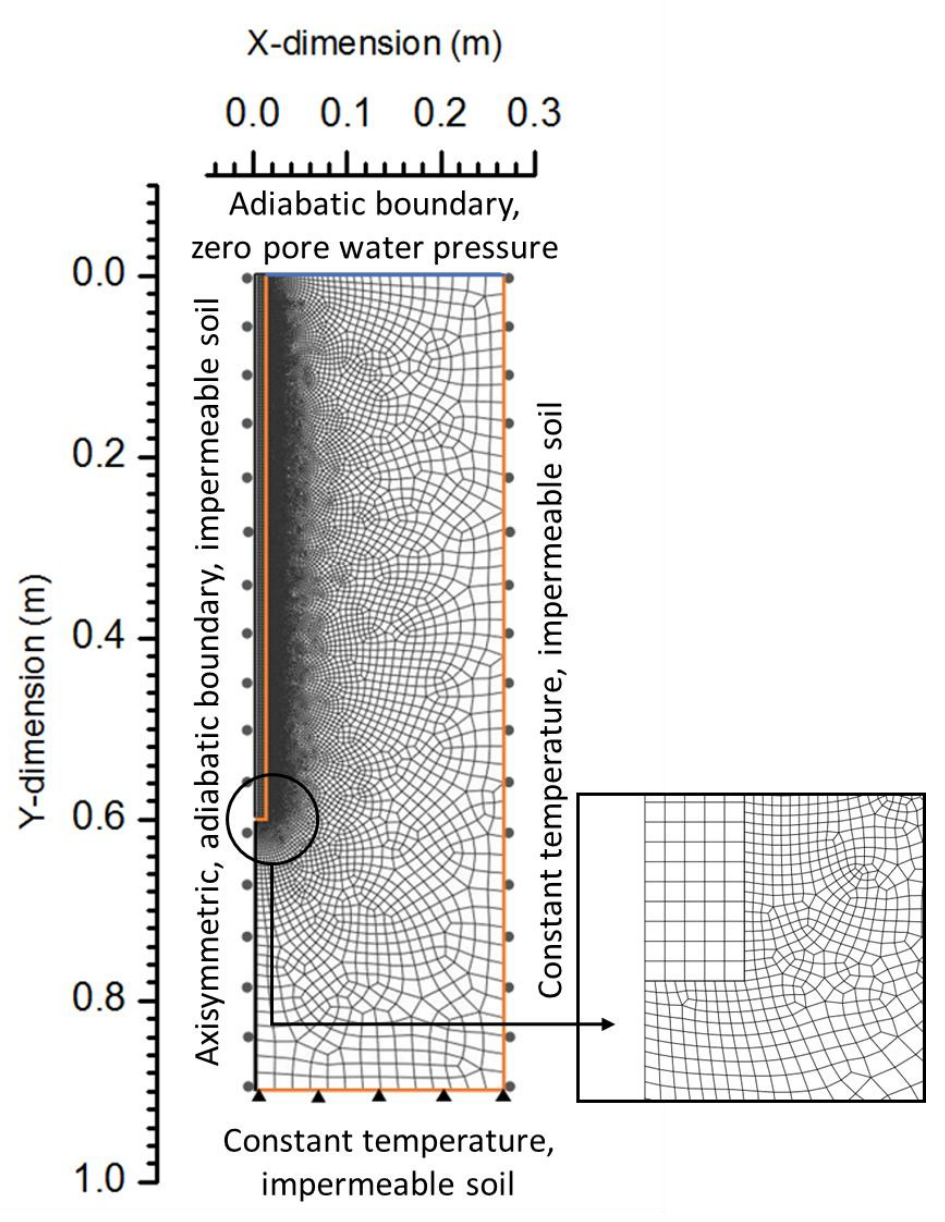

Figure 5. Geometry and boundary conditions of the numerical model

Mesh sensitivity study

253 Five different mesh convergence analyses were performed to study mesh dependency of the 254 numerical model. For the pile, uniform $1 \mathrm{~mm}, 2 \mathrm{~mm}$ and $3 \mathrm{~mm}$ seed size are applied in the 255 pile region respectively with unchanged $1 \mathrm{~mm}$ mesh size at soil side of soil-pile interface to 256 find appropriate pile mesh size. It is found that $2 \mathrm{~mm}$ mesh size for the pile was sufficient and 257 then, mesh sizes of $1 \mathrm{~mm}, 1.5 \mathrm{~mm}$ and $2 \mathrm{~mm}$ are applied into soil side of soil-pile interface 258 region which enables in total 5 different types of mesh size combinations. At the far end, 259 bottom and side of soil, the mesh seed size was set to a fixed $20 \mathrm{~mm}$ value for all simulations. 260 Here only the purely mechanical loading condition, A1, was considered for this mesh 
settlement curves for different mesh size combinations are given. The mesh "Pile $2 \mathrm{~mm}$, Soil

$2631 \mathrm{~mm}$ " is selected since it is above the threshold (i.e. Pile $2 \mathrm{~mm}$, soil $1.5 \mathrm{~mm}$ ) compared with

264 the experimental data for the pure mechanical loading. This finer mesh provides a better

265 confidence for the results from later thermo-mechanical analyses, while only slightly

266 increases the demand on computational resources.

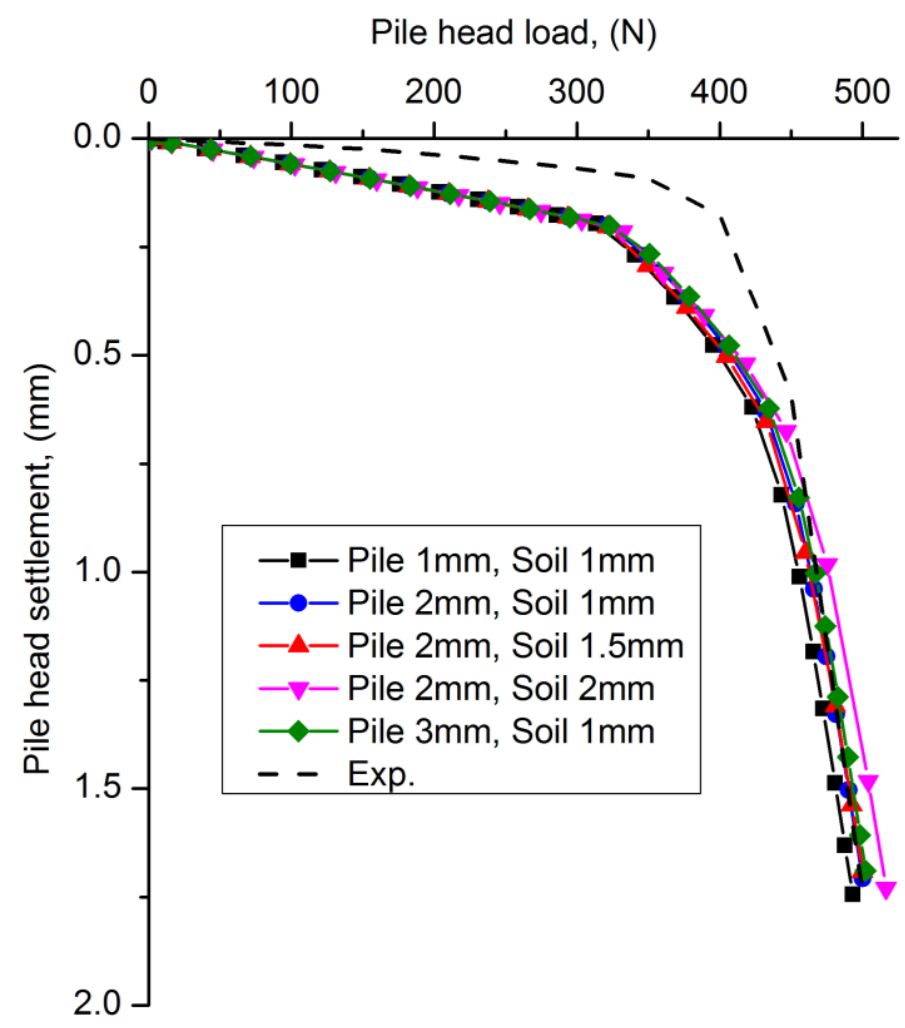

267

Figure 6. Mesh dependency results (A1)

269

RESULTS

270

Mechanical behaviour of pile

271 Experiment result (Exp.) of test A1 is shown in Figure 4. This load-settlement curve is based

272 on the settlement value at the end of each load step. After loading to $500 \mathrm{~N}$ the pile is 273 unloaded and the irreversible settlement of pile head is about $1.42 \mathrm{~mm}$. The relationship 274 between the axial load and the pile head settlement during the loading is almost linear when 
275 the axial load is smaller than $350 \mathrm{~N}$. For axial load higher than this value, pile head settlement increases significantly with the increase of axial load.

277

278 The numerical result (Num.) gives a similar behaviour of pile by using the parameters of pile 279 and soil shown in Tables 1 and 2. Analysis on the plastic points shows that during the loading 280 path, when the axial load is lower than $350 \mathrm{~N}$, only few plastic points can be observed at the 281 pile toe. Interfacial friction is approaching maximum shear stress. Loading above this value induces development of plastic zones, and this phenomenon can be observed by the quick increase of pile head settlement.

Thermo-mechanical behaviour of pile

286 In this section, the results of the tests from A2 to A5 are presented. Figure 7 shows the 287 temperature distribution corresponding to four phases of one thermal cycle: initial, heating, 288 cooling, and re-heating. These results confirm that the heat transfer between the pile and the 289 surrounding soil is mainly radial along the pile. Temperature measured at $300-\mathrm{mm}$ depth (in 290 the middle of the pile) should be then representative to study the heat transfer in this study.
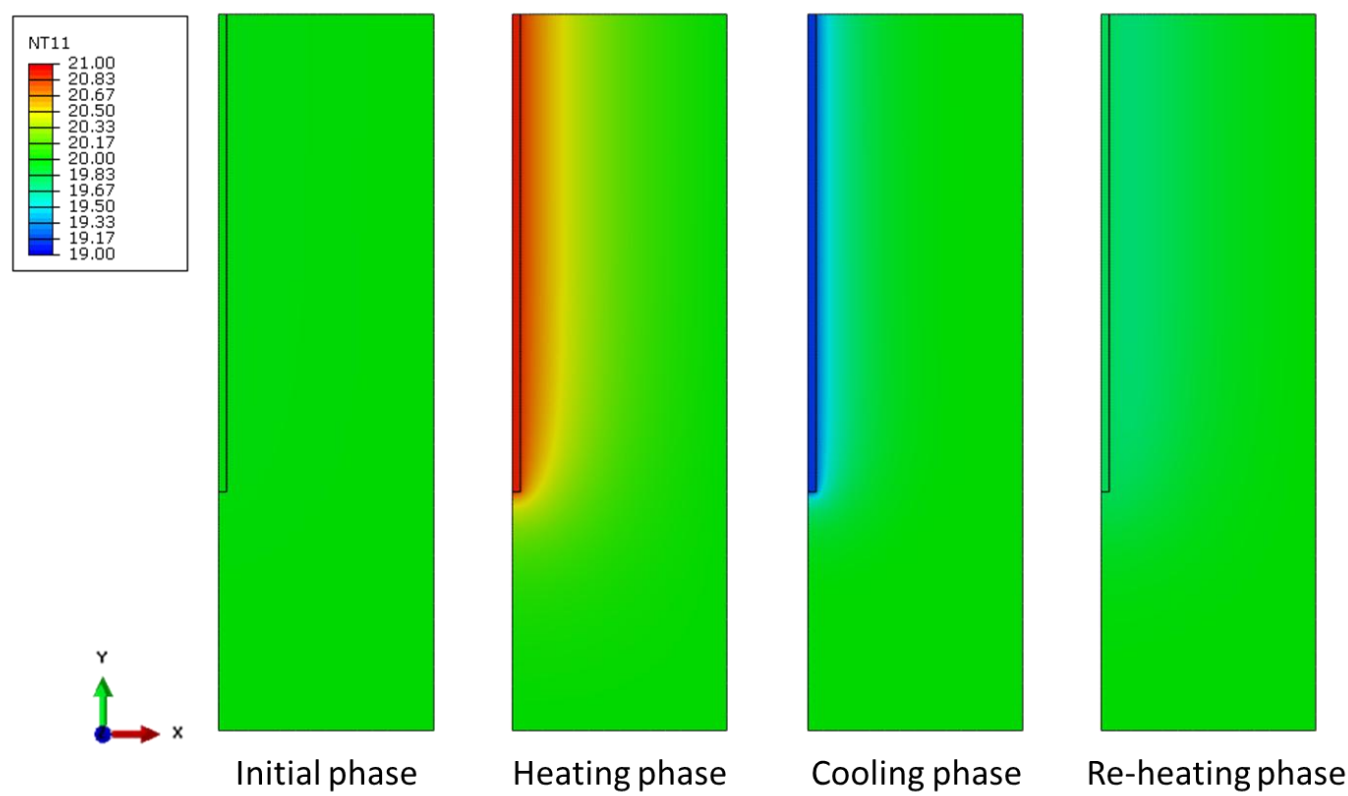
294 Actually, the Figure 8 presents the temperatures measured at different locations at 300-m 295 depth during one thermal cycle. These measurements evidence that the soil temperature 296 increases when the pile is heated and decreases when the pile is cooled. The effect of pile 297 heating/cooling is more significant for sensors located closer to the pile. The numerical results obtained in the soil are in good agreement with the experimental ones. This agreement confirms that the thermal parameters and the heat transfer mechanisms (heat conduction) used in the numerical model are appropriate. Note that the thermal parameters have been 301 determined separately in laboratory by a thermal probe.

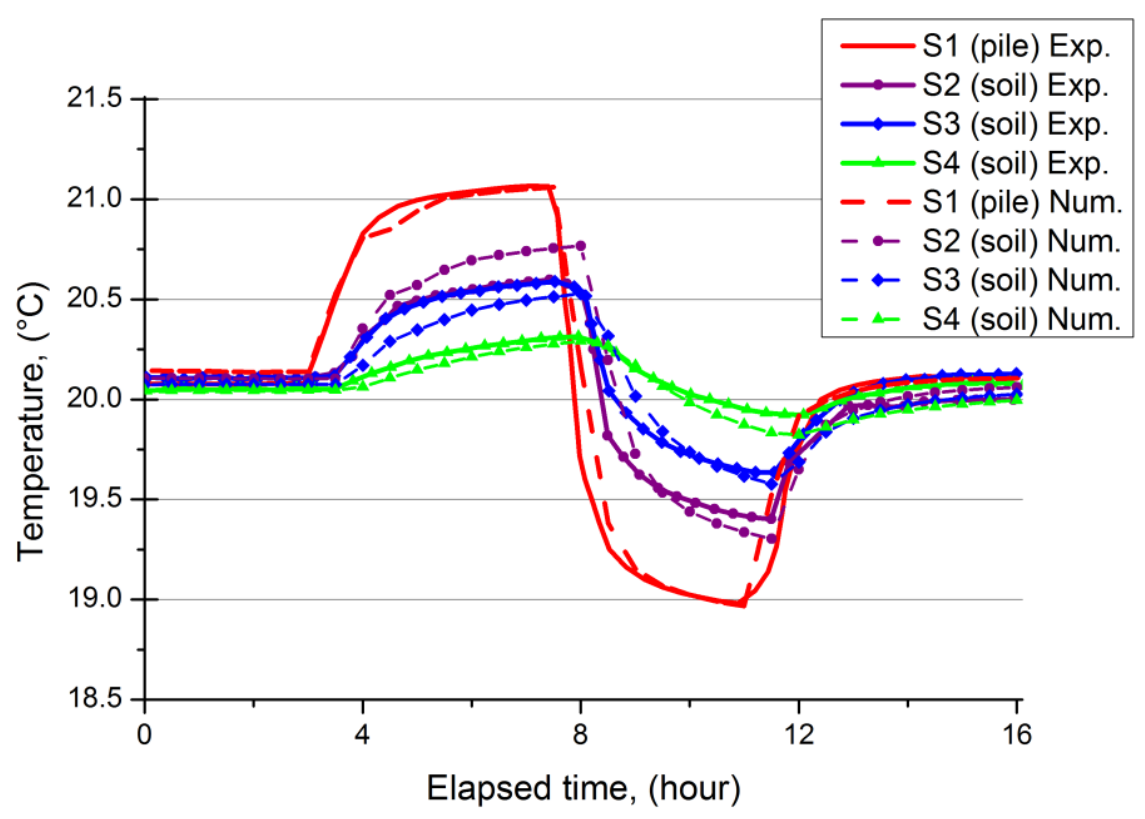

Figure 8. Temperature of pile and surrounding soil during one thermal cycle

Figure 9 shows the results of temperature and displacement of the pile over the 30 thermal cycles under different loads. It can be seen that the target temperature $\left(20^{\circ} \mathrm{C}-21^{\circ} \mathrm{C}-19{ }^{\circ} \mathrm{C}\right.$ $-20{ }^{\circ} \mathrm{C}$ ) in each thermal cycle could not be strictly respected during the first test (A2). This is related to the variation of temperature in the room. For this reason, in the subsequent tests 
309 (A3, A4, A5) the thermal isolation of the tube connecting the cryostat and the pile was 310 improved, that allowed reducing significantly the influence of room temperature on the pile

311 temperature. In Figure 9, the pile head settlement of each test is set to zero at the beginning of 312 the thermal cycles. The results show generally a pile head heave during heating and 313 settlement during cooling. However, the relation between the pile head displacement and the 314 pile temperature is not strictly reversible. Note that the temperature was controlled manually 315 and for some cycles corresponding to weekend periods the active heating phase took longer 316 than two days. Nevertheless, it seems that these longer phases do not influence significantly 317 the results.

318

319 In the numerical model, the pile temperature measured in the experiment is imposed to the 320 whole pile to simulate the thermal cycles under constant pile head load. The pile head 321 settlement obtained by the simulation is also shown in Figure 9. The numerical results show 322 equally a pile head heave during heating and settlement during cooling. More details on pile 323 head displacement during each thermal cycle and the irreversible pile head displacement are 324 shown in Figure 10 and 11. 

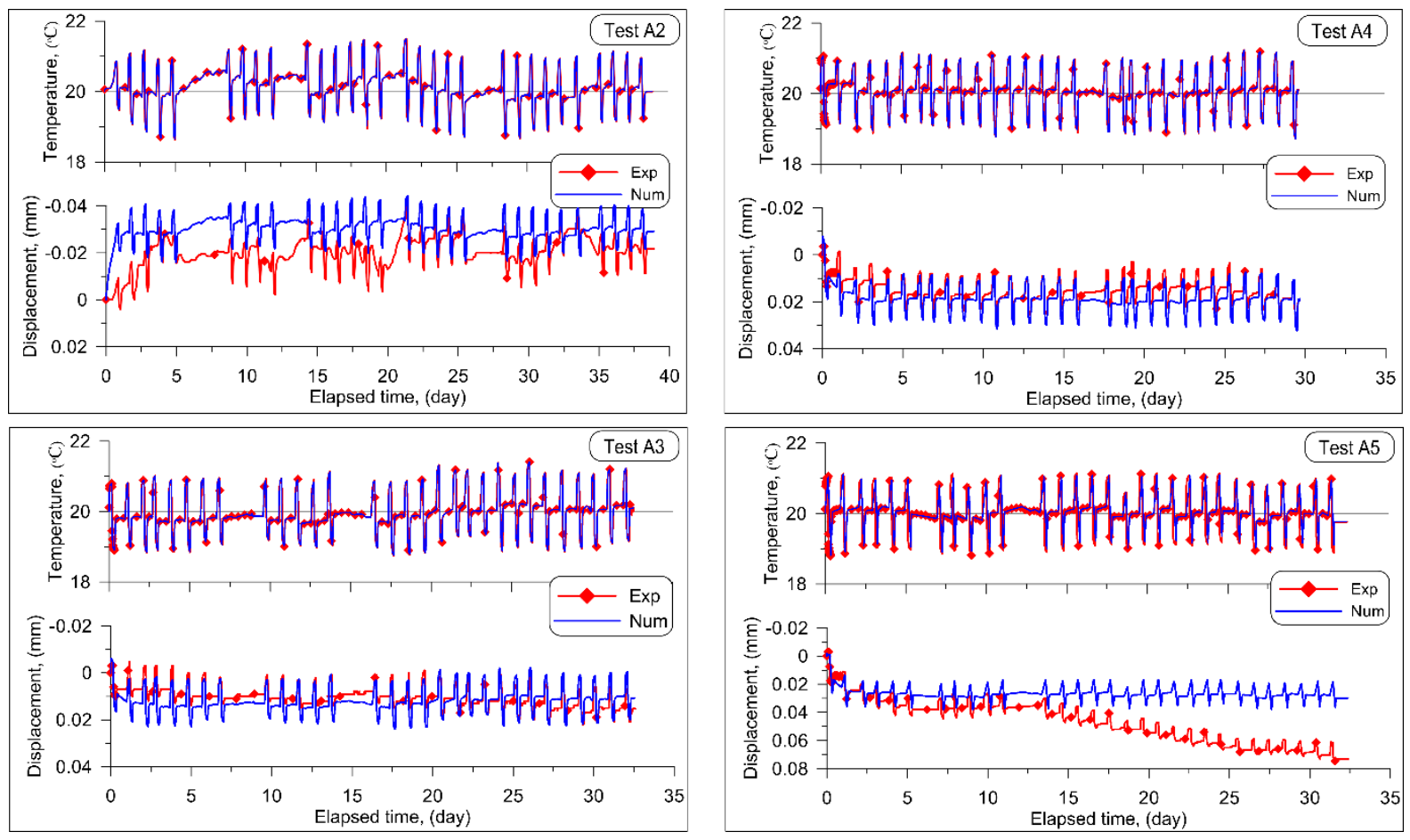

Figure 9. Temperature and pile head displacement versus elapsed time (A2-A5)

329 To better analyse the pile head displacement during each thermal cycle, in the Figure 10, it is plotted versus pile temperature for the first and the last cycles only. The free expansion curve, obtained with the assumption of a pile restrained at its toe, is also plotted. In each thermal cycle, heating induces pile head heave and cooling induces pile head settlement. For the tests A3, A4, and A5 (under constant head load), the first thermal cycle induces a significant irreversible settlement. For the case of test A2 where not head load was applied, the behaviour during the first thermal cycle is quite reversible. For the last thermal cycle, a reversible behaviour can be observed for all the tests. Besides, it can be noted that the slope of the pile head displacement versus temperature change during the cooling phase is slightly smaller than that of the free expansion curve.

339 The results obtained by the numerical simulation are generally in agreement with the experimental ones. Actually, the behaviour obtained during the last thermal cycles is strictly reversible and the first thermal cycle in the tests A3, A4 and A5 (under constant pile head 
343 (without pile head load) show a difference. In the numerical model, an irreversible pile head

344 heave was obtained after the first thermal cycle.

345
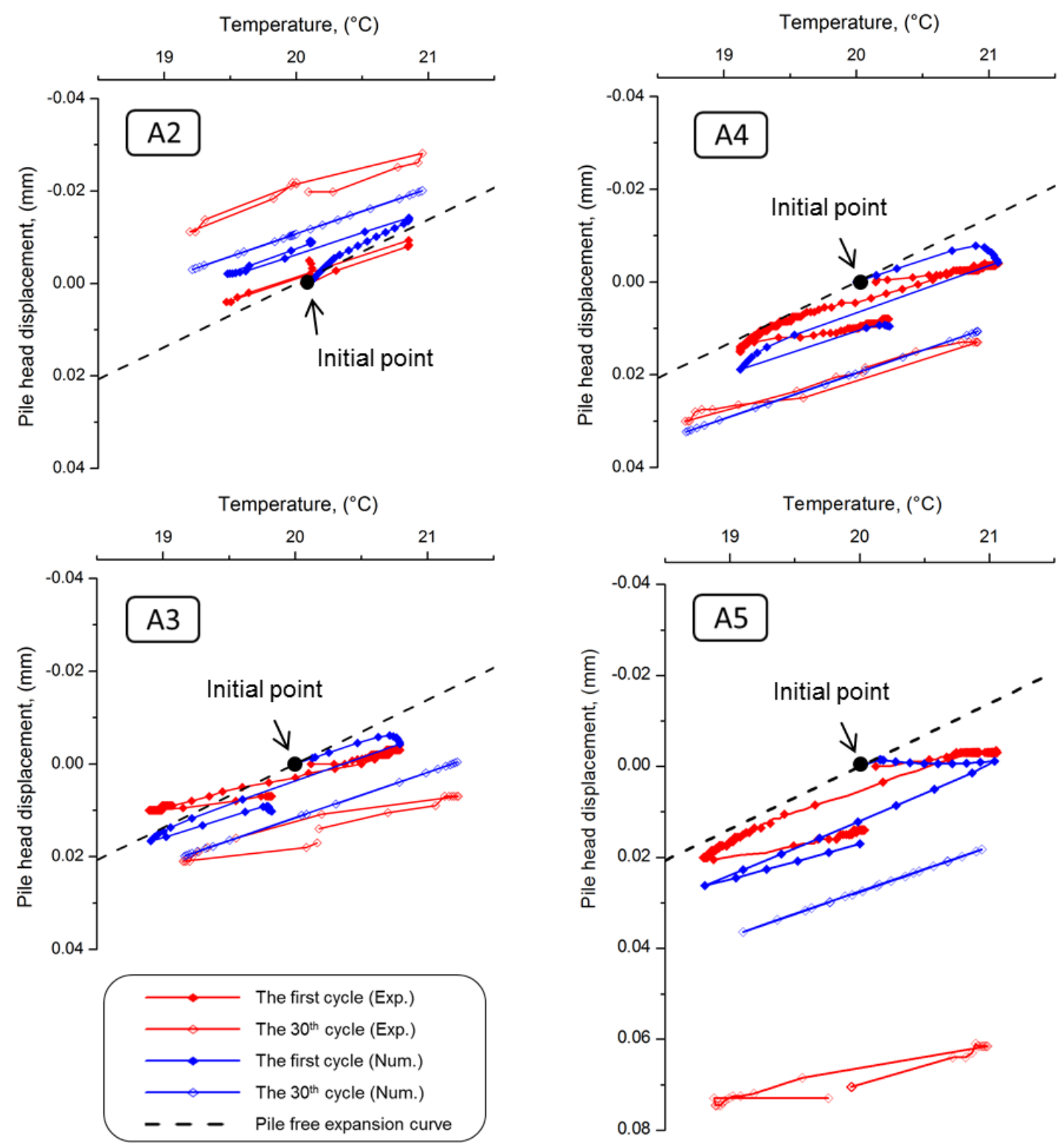

347 Figure 10. Pile head settlement versus pile temperature during the first and the $30^{\text {th }}$ cycles

349 The irreversible pile head displacement is plotted versus the number of cycles in the Figure

350 11. For a better comparison with full-scale experiments, it is also normalised with the pile 
351 diameter. For the test A2, the first cycle induces pile head heave up to $0.15 \%$ of pile diameter

352 with the numerical model. Afterward, the pile behaviour remains reversible during thermal

353 cycles. However, with the physical model, the first cycle induces only very small pile heave

$354(0.03 \%$ of pile diameter). But pile heave continues to increase during the subsequent cycles 355 and reaches $0.20 \%$ of pile diameter after four cycles. For the tests A3 and A4, the first 356 thermal cycles induce significant irreversible settlement. This latter become negligible for the 357 subsequent cycles. The behaviour of the pile in the test A5 is also similar to that of tests A3 358 and A4. However, after the tenth cycle, the irreversible settlement increases continuously 359 with the increase of the number of cycles. Besides, it can be noted that the irreversible 360 settlement depends on the pile head load; the higher the pile head load the higher the 361 irreversible settlement. For the test A5, the sudden increase of irreversible settlement from 362 the $10^{\text {th }}$ cycle should be related to some technical problems. The possible causes of problems 363 occurred could be: tilting of the pile at high cumulative settlement, failure of soil around the 364 pile toe, or other physico-chemical phenomena that occur in soil after a long period (several 365 months).

367 The results obtained by the numerical simulation are generally in good agreement with the experimental ones. The only difference is related to the test A5 where the pile head irreversible displacement remains constant event after the tenth cycle in the numerical 370 simulation. 


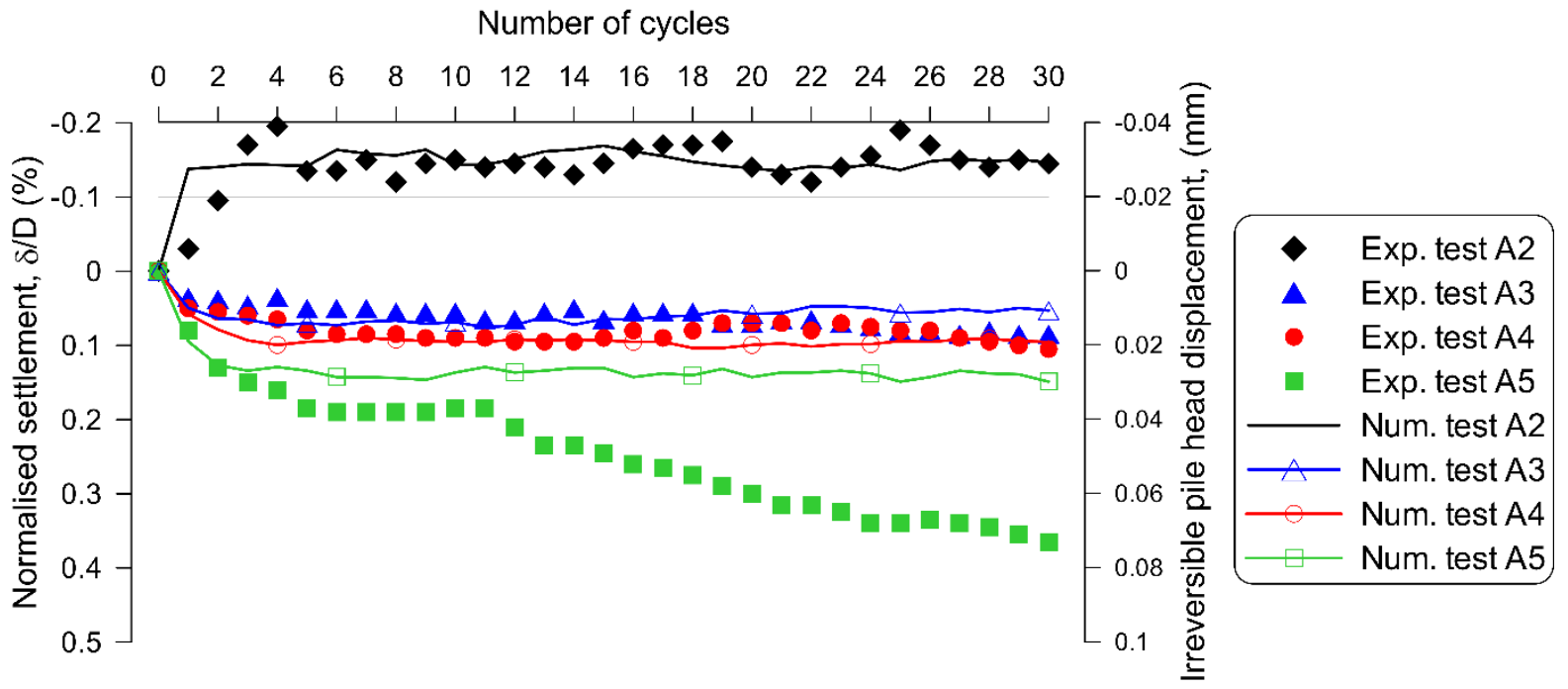

Figure 11. Irreversible pile head displacement versus number of thermal cycles

374 The long-term performance of the pile is further illustrated according to the numerical results.

375 Vertical displacement of pile length on heating phase $(H)$, cooling phase $(C)$ and reheating 376 phase (R) are plotted in Figure 12. The first, second, twentieth and thirtieth thermal cycles are 377 selected here because simulation results show that the majority of irreversible settlement 378 happens within the first-three cycles and is relatively stable in the rest of thermal cycles. Note 379 that the vertical displacement of pile is assumed zero at the beginning of first cycle in order to 380 be consistent with Figure 11. It is obvious that heating and cooling the pile cause displacement distribution to be mirror-reflecting each other and vertical displacement remains constant along pile length in reheating phase. The time evolution of displacement profile is stabilised over a few cycles with a null point at about $430 \mathrm{~mm}$ beneath the top surface. 


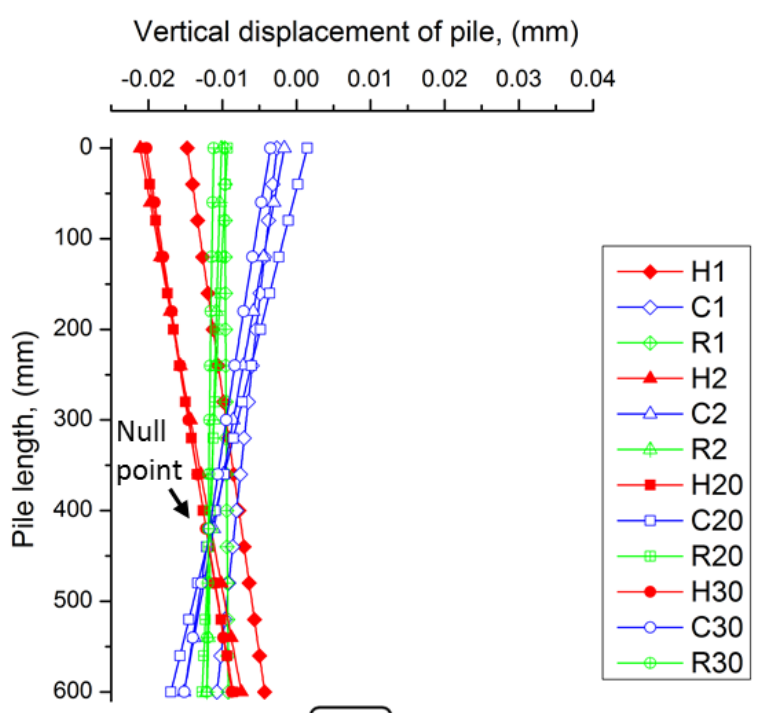

A2

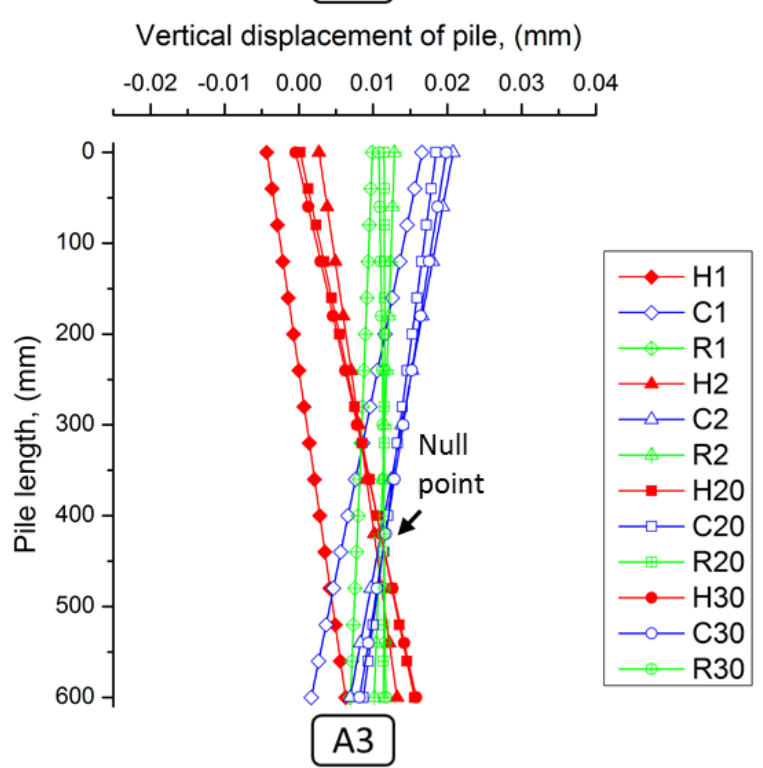

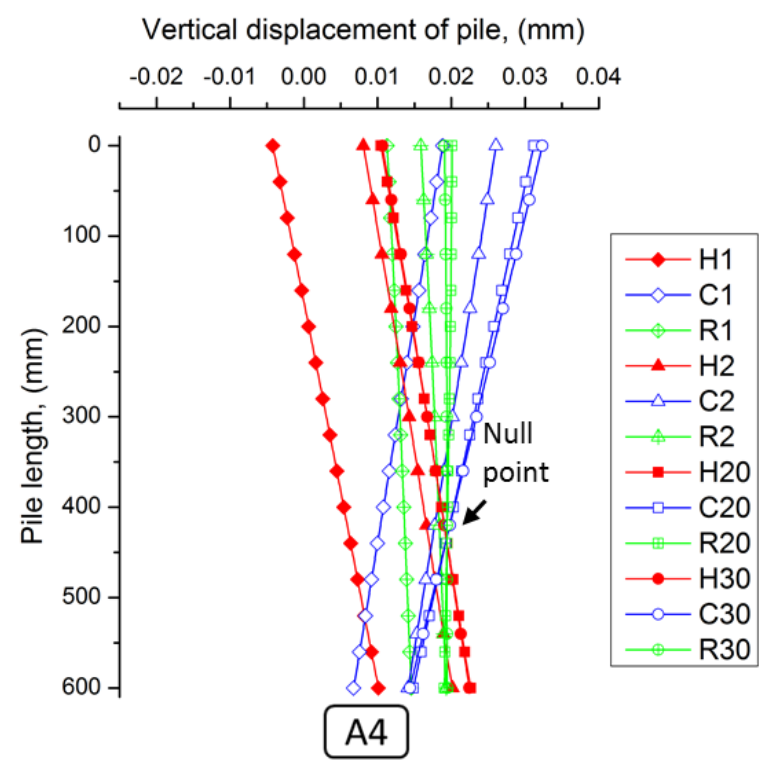

Vertical displacement of pile, $(\mathrm{mm})$

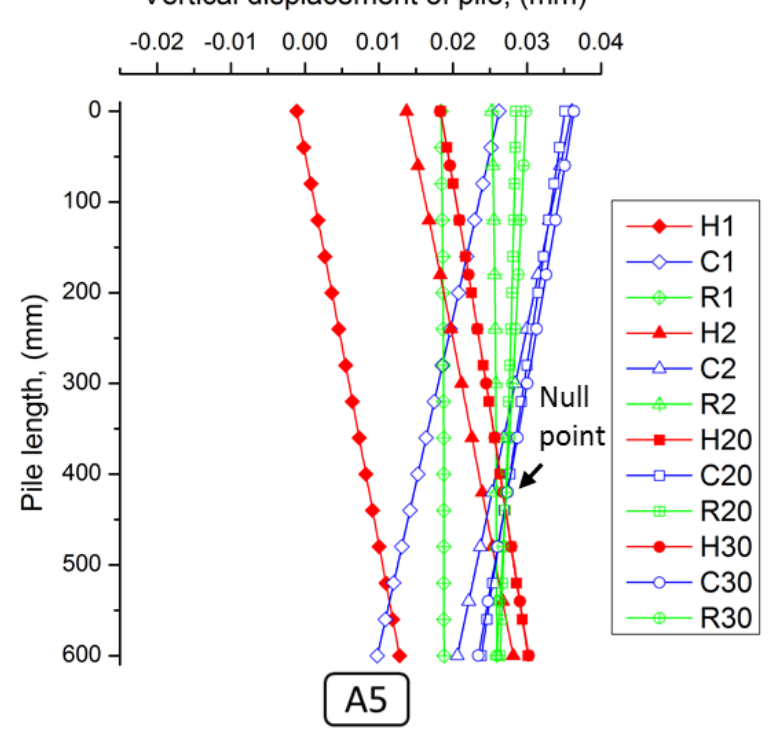

Figure 12. Vertical displacement along the pile length (numerical results)

387 The total vertical stress along the pile length under different thermal cycles obtained from the

388 numerical simulation is presented in Figure 13. Only the results obtained from the first and 389 the last cycles are presented for clarity. Generally, heating the pile induces a slight increase of 390 vertical stress and cooling causes a decrease in vertical stress distribution along the pile 391 length. The behaviour obtained during the first cycle of test A2 is slightly different; heating 392 induces a decrease of vertical stress and cooling decreases again this latter. Besides, the 

heating, cooling and reheating phases.

395
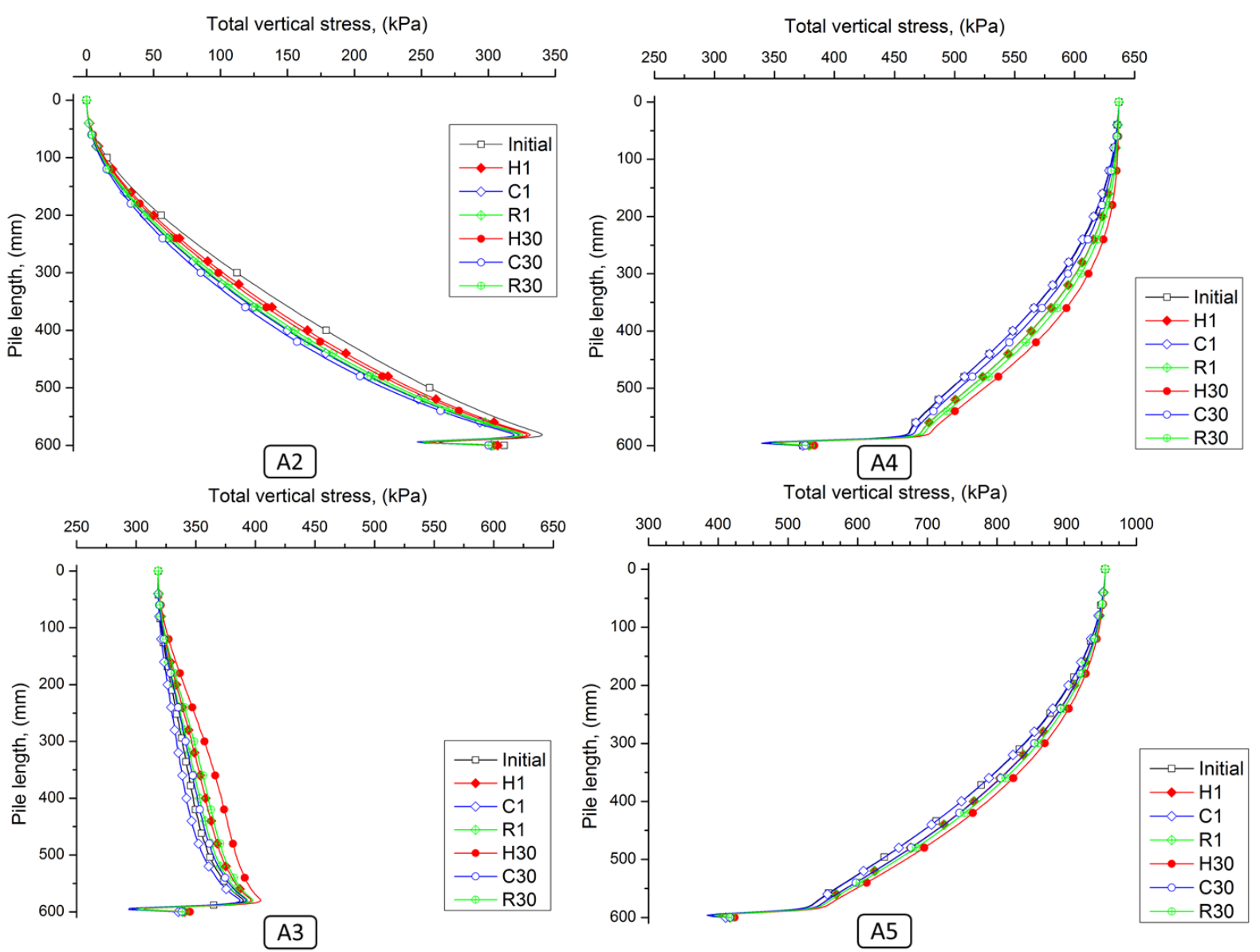

Figure 13. Thermal effect on the total vertical stress along the pile length (numerical results)

DISCUSSION

In the mechanical test paths (test A1), the material parameters for the numerical simulation are adopted from Lv et al. (2017). From the results, it is obvious that the estimated bearing capacity is in agreement with the experimental results (Figure 4). A carefully estimated 404 lateral stress coefficient $\left(K_{0}\right)$ is important to consider the compaction process in physical model. 
407 In the test A2, the upward displacement of pile (as shown in Figure 9) during heating/cooling cycles, observed on both physical and numerical models, can be explained by the stress state shown in Figure 13. Actually, the test A2 starts after the mechanical unloading path of test

410 A1. At the end of the unloading path, the pile is still subjected to compressive stress (up to $411300 \mathrm{kPa}$ at its toe). Thermal cycles in test A2 induce thermal dilation/contraction of the pile.

412 This movement would release this compressive stress and heave the pile. The results shown in Figure 13 evidence this stress release after thermal cycles.

415 In the subsequent tests (A3, A4, A5), irreversible settlement was observed during the first 416 thermal cycles. These results are in agreement with those observed by $\mathrm{Ng}$ et al. (2014) (using 417 centrifuge modelling) and Vieira \& Maranha (2016) by using the finite element method. 418 However, only five thermal cycles were investigated in these works. Actually, the axial stress 419 profiles plotted in Figure 13 show that these thermal cycles increase the axial stress along the 420 pile. That means the thermal dilation/contraction of the pile facilitate the transmission of axial 421 pile head load to the pile toe. In the present works, both numerical and physical models show that the pile settlement becomes reversible under thermal cycles at high number of cycles (except for the test A5).

425 The numerical model shows behaviour similar to that obtained by physical model; the pile settlement progressively achieves stable state due to densification process in each thermal cycle. Especially the first thermal cycle shows good agreement with the experimental result (Figure 10). The explanation of why numerical simulation is able to predict progressive settlement owes to the use of the modified Cam-clay model as the constitutive model for soil. 430 The Cam-clay criterion follows the poro-plasticity rule that could more effectively simulate 
densification process during thermal cyclic loads. Whereas Mohr-Coulomb model may not well describe such soil behaviour (Yavari et al., 2014). Therefore, the present numerical prediction of long-term thermal cyclic settlement of energy pile is able to predict experimental data with relatively good agreement.

The results of Figure 10 show that the slope of the pile head displacement versus temperature change during the cooling phase is slightly smaller than that of the free expansion curve. Actually, similar tests on dry sand have shown that this slope is similar to the free expansion curve (Kalantidou et al., 2012; Yavari et al., 2014). The behaviour observed in the present work can be explained by the results shown in Figure 12. Actually, the null-point does not locate at the pile toe but at $400-450 \mathrm{~mm}$ depth. For this reason, the pile head displacement does not correspond to the free expansion of the whole pile length.

444 In the present work, the numerical model was able to reproduce correctly the thermo445 mechanical behaviour of a small-scale energy pile under several thermal cycles. Note that the 446 range of the temperature variation in the physical model was limited to $\pm 1{ }^{\circ} \mathrm{C}$. This value is 447 much smaller than full-scale application (up to $\pm 20^{\circ} \mathrm{C}$ ) in order to respect the scale effect. 448 Within this limited range of temperature variation, the soil parameters can be assumed to be independent of temperature. However, for a higher temperature variation, the temperature 450 change can slightly modify the soil properties (Tang et al., 2008; Vega \& McCartney, 2015; 451 Hong et al., 2016; Yavari et al., 2016b; Jacinto \& Ledesma, 2017; Ghorbani et al., 2019). 452 The use of the present numerical model to predict the behaviour of real-scale energy 453 foundations should consider this aspect. 
455 Results obtained in the present study would be helpful for studies on various types of thermo456 active geostructures (Hoyos et al., 2015; Narsilio et al., 2017; Sanchez et al., 2017; Angelotti and Sterpi, 2019; Baralis et al., 2019)

\section{CONCLUSIONS}

460 The long-term thermo-mechanical behaviour of energy pile is investigated in the present work by using a small-scale model pile (physical modelling) and the finite element method (numerical modelling). The following conclusions can be drawn: serviceability design of geothermal energy piles.

474

\section{5}


Abuel-Naga H, Raouf MIN, Raouf AMI, Nasser AG (2015) Energy piles: current state of knowledge and design challenges, Environmental Geotechnics, 2(4), 195- 210.

AFNOR (1999) Essai statique de pieu isolé sous un effort axial, NF P 94-150-1, 28 pages.

Angelotti A and Sterpi D (2019). On the performance of energy walls by monitoring assessment and numerical modelling: a case in Italy. Environmental Geotechnics, doi: 10.1680/jenge.18.00037.

Baralis M, Barla M, Bogusz W, Di Donna A, Ryzynski G \& Zerun M (2019). Geothermal potential of the NE extension Warsaw (Poland) metro tunnels. Environmental Geotechnics, doi: 10.1680/jenge.18.00042.

Bidarmaghz A, Francisca FM, Makasis N and Narsilio GA (2016) Geothermal energy in loess, Environmental Geotechnics, 3(4), 225 - 236, doi:10.1680/jenge.15.00025.

De Santayana FP, de Santiago C, de Groot M, Uchueguia J, Acros JL and Badenes B (2019). Effect of thermal loads on pre-cast concrete thermopile in Valencia, Spain, Environmental Geotechnics, doi: 10.1680/jenge.17.00103.

Di Donna A, and Laloui L (2015) Numerical analysis of the geotechnical behaviour of energy piles, Int. J. Numer. Anal. Methods Geomech., 39(8), 861-888, doi:10.1002/nag.2341.

Ghorbani J, El-Zein A and Airey DW (2019) Thermo-elasto-plastic analysis of geosynthetic clay liners exposed to thermal dehydration. Environmental Geotechnics, doi: 10.1680/jenge.17.00035.

Hoyos LR, DeJong JT, McCartney JS, Puppala AJ, Reddy KR \& Zekkos D (2015) Environmental geotechnics in the US region: a brief overview. Environmental Geotechnics, 2(6), 319 - 325, doi: 10.1680/envgeo.14.00024.

Hong PY, Pereira JM, Cui YJ and Tang AM (2015) A two-surface thermomechanical model for saturated clays. International Journal for Numerical and Analytical Methods in Geomechanics, 40(7), 1059-1080, doi: 10.1002/nag.2474.

Jacinto AC and Ledesma A (2017). Thermo-hydro-mechanical analysis of a full-scale heating test. Environmental Geotechnics, 4(2), 123 - 134, doi: 10.1680/jenge.15.00049.

Kalantidou A, Tang AM and Pereira JM (2012) Preliminary study on the mechanical behaviour of heat exchanger pile in physical model. Géotechnique, 62(1), 1047-1051, doi.org/10.1680/geot.11.T.013.

Laloui L, Nuth M and Vulliet L (2006) Experimental and numerical investigations of the behaviour of a heat exchanger pile. International Journal for Numerical and Analytical Methods in Geomechanics, 30(8) 763-781, doi: 10.1002/nag.499 
Lv YR, Ng CWW, Lam SY, Liu HL and Ma LJ (2017) Geometric Effects on Piles in Consolidating Ground: Centrifuge and Numerical Modeling. Journal of Geotechnical and Geoenvironmental Engineering, 143(9), 04017040.

Narsilio GA, Sanchez M, Alvarellos J and Guimaraes L (2017) Editorial: XV Pan-American Conference: selected papers on energy geotechnics. Environmental Geotechnics, 4(2), 67 - 69, doi: 10.1680/jenge.2017.4.2.67.

Ng, CWW, Shi C, Gunawan A, and Laloui L (2014) Centrifuge modelling of energy piles subjected to heating and cooling cycles in clay, Géotechnique Letters, 4(4) 310-316, doi:10.1680/geolett.14.00063.

Ng CWW, Ma QJ and Gunawan A (2016) Horizontal stress change of energy piles subjected to thermal cycles in sand. Computers and Geotechnics, 78 (2016), 54-61, doi:10.1016/j.compgeo.2016.05.003.

Nguyen VT, Tang AM and Pereira JM (2017) Long-term thermo-mechanical behavior of energy pile in dry sand. Acta Geotechnica, 12(4), 729 - 737.

Olgun CG, Ozudogru TY, Abdelaziz SL and Senol A (2015) Long-term performance of heat exchanger piles, Acta Geotechnica, 10(5), 553-569, doi:10.1007/s11440-014-0334-z.

Pasten C, Shin H, and Santamarina JC (2013) Long-Term Foundation Response to Repetitive Loading, J. Geotech. Geoenvironmental Eng., 140(4), 4013036, doi:10.1061/(ASCE)GT.1943-5606.0001052.

Pasten C, and Santamarina JC (2014) Thermally Induced Long-Term Displacement of Thermoactive Piles, J. Geotech. Geoenvironmental Eng., 140(5), 6014003, doi:10.1061/(ASCE)GT.1943-5606.0001092.

Saggu R, and Chakraborty T (2015) Cyclic Thermo-Mechanical Analysis of Energy Piles in Sand. Geotechnical and Geoogical Engineering, 33(2), 321-342, doi:10.1007/s10706014-9798-8.

Sanchez M, Falcao F, Mack M, Pereira JM, Narsilio GA and Guimaraes L (2017) Salient comments from an expert panel on energy geotechnics. Environmental Geotechnics, 4(2), 135 - 142, doi: 10.1680/jenge.16.00008.

Suryatriyastuti ME, Mroueh H, and Burlon S (2014) A load transfer approach for studying the cyclic behavior of thermo-active piles. Computers and Geotechnics, 55, 378-391, doi:10.1016/j.compgeo.2013.09.021.

Tang AM, Cui YJ and Barnel N (2008) Thermo-mechanical behaviour of compacted swelling clay. Géotechnique, 58(1) 45-54, doi: 10.1680/geot.2008.58.1.45

Vega A and McCartney JS (2015) Cyclic heating effects on thermal volume change of silt. Environmental Geotechnics, 2(5), 257 - 268, 10.1680/envgeo.13.00022. 
Vieira A and Maranha JR (2016) Thermoplastic Analysis of a Thermoactive Pile in a Normally Consolidated Clay. International Journal of Geomechnics., 17(1) 4016030, doi:10.1061/(ASCE)GM.1943-5622.0000666.

552 Yavari N, Tang AM, Pereira JM and Hassen G (2014) Experimental study on the mechanical behaviour of a heat exchanger pile using physical modelling, Acta Geotechnica, 9(3), 385-398, doi:10.1007/s11440-014-0310-7.

Yavari N, Tang AM, Pereira JM and Hassen G (2016a), Mechanical behaviour of a smallscale energy pile in saturated clay, Géotechnique, 66(11), 878-887, doi:10.1680/jgeot.15.T.026.

Yavari N, Tang AM, Pereira JM and Hassen G (2016b) Effect of temperature on the shear 559 strength of soils and soil/structure interface. Canadian Geotechnical Journal, 53(7), 560 1186-1194, doi:10.1139/cgj-2015-0355.

561

Wehnert M and Vermeer PA (2004) Numerical analyses of load tests on bored piles.

562 Numerical methods in geomechanics-NUMOG IX, 505-511.

563 